\title{
Tattoo Inks: Legislation, Pigments, Metals and Chemical Analysis
}

\author{
Gerald Prior
}

CTL Bielefeld GmbH, Bielefeld, Germany

\begin{abstract}
Legal limits for chemical substances require that they are linked to clearly defined analytical methods. Present limits for certain chemicals in tattoo and permanent makeup inks do not mention analytical methods for the detection of metals, polycyclic aromatic hydrocarbons or forbidden colourants. There is, therefore, no established method for the determination of the quantities of these chemicals in tattoo and permanent make-up inks. Failing to provide an appropriate method may lead to unqualified and questionable results which often cause legal disputes that are ultimately resolved by a judge with regard to the method that should have been applied. Analytical methods are tuned to exactly what is to be found and what causes the health problems. They are extremely specific. Irrespective of which is the correct method for detecting metals in tattoo inks, the focus should be on the actual amounts of ink in the skin. $\mathrm{CTL}^{\circledR}$ has conducted experiments to determine these amounts and these experiments are crucial for toxicological evaluations and for setting legal limits. When setting legal limits, it is essential to also incorporate factors such as daily consumption, total uptake and frequency
\end{abstract}

of use. A tattoo lasts for several decades; therefore, the limits that have been established for heavy metals used in drinking water or soap are not relevant. Drinking water is consumed on a daily basis and soap is used several times per week, while tattooing only occurs once.

๑) 2015 S. Karger AG, Basel

\section{Introduction}

$\mathrm{CTL}^{\circledR}$ Bielefeld $\mathrm{GmbH}$ is the leading commercial laboratory for the investigation of tattoo and permanent make-up (PMU) inks. This laboratory has been conducting tests in this field for over a decade and has customers based in locations ranging from Europe to the US, Asia and Australia. CTL ${ }^{\circledR}$ not only tests products but also helps manufacturers to improve quality and meet legislative requirements. The managing director of CTL ${ }^{\circledR}$, Dr. Gerald Prior, has recently published a book [1] containing more in-depth details on many more issues than are mentioned here. 
The key question when evaluating the potential risks of tattoo inks is how much ink is in the skin as a result of the tattooing. A test was conducted by CTL $^{\circledR}$ using a marker in a tattoo ink. A tattoo was performed by a professional tattoo artist, which left an average amount of $0.4 \mathrm{mg} / \mathrm{cm}^{2}$ of ink in the skin [1]. The size of the tattoo was $910 \mathrm{~cm}^{2}$. These results can be used to determine the actual quantities of contaminants in the skin.

An example using the data from the abovementioned experiment demonstrates basic calculations for determining ink amounts in skin. A product has been banned from the EU market because it contains $12.2 \mathrm{mg} / \mathrm{kg}$ of nickel (Germany, Rapex Reference 24 A12/1380/12). If the abovementioned large tattoo of $910 \mathrm{~cm}^{2}$ in size had been tattooed on the back of a person using this banned ink, they would have had a total of 0.0057 $\mathrm{mg}$ of nickel in their skin. The average content of nickel per $\mathrm{cm}^{2}$ would have been $0.000006 \mathrm{mg}$. Whether it is reasonable to ban a tattoo ink containing $12.2 \mathrm{mg} / \mathrm{kg}$ of nickel is questionable.

The basis for the ban of inks are limits contained in two resolutions published by the Council of Europe (CoE), ResAP(2003)2 [2] and ResAP(2008)1 [3]. The limit defined for nickel is 'as low as technically achievable'. This value is not only dependent on the method used for the analysis but also on the product used. For certain pigments, values of zero can be achieved, but this is not true for all pigments. Iron oxide pigments always contain minor amounts of nickel as impurities. The nickel in these products is not soluble and therefore, it is unclear whether it causes allergic reactions.

\section{Resolutions ResAP(2003)2 and ResAP(2008) 1 of the CoE}

The resolutions published by the CoE contain limits for contaminants, bans for several chemicals and instructions for labelling products. The most important requirement is that inks must not endanger the health or safety of persons or the environment. Further, inks must not contain carcinogenic, mutagenic or reproduction-toxic substances of categories 1,2 and 3 as classified in the EU Directive 67/548/EEC. Limits have also been set for polycyclic aromatic hydrocarbons (PAHs) and metals. Certain aromatic amines that may be released from colourants and certain colourants themselves are forbidden.

Most interesting is the fact that the limits for metals in these resolutions are exceedingly lower than those for food colourants, according to the Directive 95/45/EEC. For example, the amount of chromium allowed in food colourants is $100 \mathrm{mg} /$ $\mathrm{kg}$, while for tattoo inks it is $0.2 \mathrm{mg} / \mathrm{kg}$ according to ResAP(2008)1. This means that food colourants may contain 500 times more chromium than tattoo ink. In addition, 25 times more cadmium is allowed in food colourants than in tattoo ink. The reasoning for the set limits for tattoo and PMU inks is hard to understand.

The resolutions of the $\mathrm{CoE}$ also do not mention any methods for the analysis of metals, PAHs or the forbidden colourants. This is a sincere drawback and is discussed later in detail.

\section{Pigments}

Pigments used in the tattoo and PMU industries are both organic and inorganic. Organic pigments are mainly synthetically made and contain carbon. Inorganic pigments are minerals that are also often found in nature. The main inorganic pigments are titanium dioxide, barium sulphate and iron oxides. Titanium dioxide and barium sulphate are used for white colours or to brighten darker shades. Iron oxides are used to achieve the colours red, brown and black and are often used for colours similar to the shade of the skin. These pigments are all insoluble in aqueous solutions and precipitate in the skin.

A major issue is the purity of the barium sulphate used. Impurities of soluble barium salts, e.g. 
barium carbonate, can cause respiratory paralysis, cardiac arrest or death [4-6]. It is therefore of utmost importance that barium sulphate is analysed for soluble barium salts as described for medical (barium meal) or cosmetic products [7, 8]. Failing to do so may cause death. The severe problem arising from impure barium sulphate is not at all addressed in the resolutions. For some, this could be a deadly omission.

Iron oxide pigments are found in nature and all contain nickel as an impurity. They are refined before use to achieve a high degree of purity and to obtain a defined colour. The nickel contained in iron oxides is not soluble and is seemingly part of the crystal structure [1]. Therefore, it is questionable whether the contained nickel can cause allergic reactions.

Several different classes of organic pigments are used in tattoo and PMU inks, including azo pigments, polycyclic pigments, and phthalocyanine pigments. The frequently used black pigment is the main source of carcinogenic PAHs. Its purity is dependent on the source and manufacturing process. Although there is only one colour index (CI) number for black pigment, CI 77266, it has many physical variations that are all listed under the same CI number. Therefore, the CI number gives only limited information about a product and its quality. The purity and structure of a black pigment and whether it contains problematic PAHs can in no way be derived from the CI number. This information would require detailed chemical analysis, but again, no methods are mentioned in the resolutions of the CoE.

Azo pigments are mainly used to achieve bright and vibrant colours and can be a source of carcinogenic amines if the azo bond is cleaved to produce such amines. Azo colourants pose a smaller health risk than the amines that they produce. Cancer-causing amines were documented in the colour and textile dyeing industry more than a century ago [9]. There are indications that only soluble azo colourants are cleaved to form carcinogenic amines in the human body. Insolu- ble pigments, such as those used in tattoo and PMU inks, appear to be stable [10]; therefore, they should not lead to health problems. The question remains as to whether solubility is generally equivalent to bioavailability.

Phthalocyanine pigments have a base structure similar to several pigments found in nature, including haem, which gives the red colour to blood, and green chlorophyll in plants. The pigments used in tattoo inks contain copper as a central atom in their structures and the copper ion is firmly bonded to the base structure, similar to haem, which contains iron, and chlorophyll, which contains magnesium as a central atom. Microwave analysis of these copper-based pigments have shown copper levels of more than $1,000 \mathrm{mg} / \mathrm{kg}$ but have not revealed the amounts of soluble copper in products. Because the copper is firmly bound to the base structure, it is unclear whether it causes health problems. On the other hand, soluble copper should be limited. Here again, the microwave digestion method has not produced any useful results or information.

\section{Analysis of Metals in Tattoo Inks}

There are two methods being used on the market for the analysis of metals in tattoo and PMU inks. They differ considerably with regard to the first part of the procedure, which is called the work-up. The procedures for the final analysis of the metals themselves are identical. Authorities use a method commonly known as microwave digestion. The work-up of this method uses strong acids and a microwave oven to digest the sample. Due to the strong acids and high temperature and pressure, nearly everything can be digested and broken down into their elements. Even high-quality steels and jewellery can be dissolved using this fierce method. The form of a metal cannot be established using this method. It may have been soluble in water or insoluble and part of a crystal structure of a pigment or it may even have been in an organic or a mineral form. In 2009, CTL $^{\circledR}$ devised an 
Fig. 1. Different work-up methods for the analysis of metals in tattoo and PMU inks.

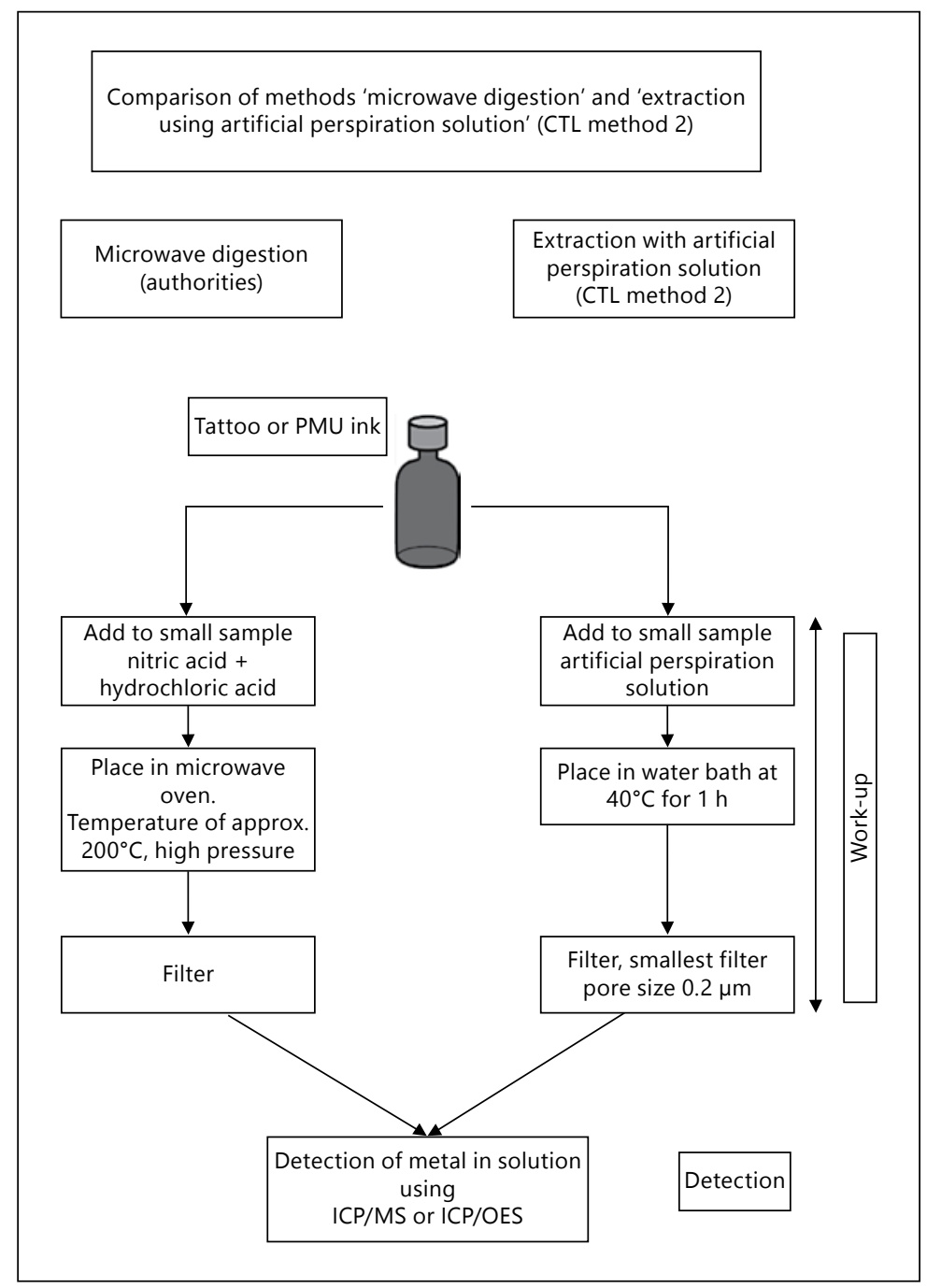

alternative work-up method for microwave digestion for analysing metals in tattoo and PMU inks which only detects soluble metals. This method involves extraction with an artificial perspiration solution and microfiltration [1]. It is quite similar to the legal method used for the release of nickel in jewellery [11]. For nickel in jewellery, only the nickel that is soluble in an artificial perspiration solution is detected. Figure 1 demonstrates the different work-up methods for microwave digestion and extraction with artificial perspiration.

\section{Limitations and Weaknesses of the Resolutions}

The resolutions ResAP(2003)2 and ResAP(2008)1 are only recommendations and are not legally binding. Nevertheless, several manufacturers use the limits mentioned in $\operatorname{ResAP}(2008) 1$ as a minimum standard for their inks.

A major drawback of the resolutions are the missing analytical methods. Due to this lack of information, it is unclear what the limits mean 
and what they refer to; for example, whether they pertain to soluble metals or insoluble metals and other chemicals. If soluble chemicals are of concern, then the solvent in which they are to be solubilised must be defined, e.g. artificial perspiration or hydrochloric acid, such as that in the stomach. The legal methods for detecting metal in toys [12] and in jewellery [11] are specific in this respect. The method for toys only detects metals that are soluble in the hydrochloric acid of the stomach, and for jewellery, only released soluble nickel is detected.

A previous publication [13] has described the limits for allergic reactions to metals in products which are based on soluble nickel, not insoluble nickel. The dose-response tests conducted used soluble nickel salts, such as nickel sulphate and nickel chloride, applied directly on the skin [14]. Furthermore, the missing analytical methods in the resolutions are responsible for much confusion on the market, many unjust and illegal market recalls and arbitrary decisions by authorities. The resolutions have not been implemented into national law in any of the EU member states and they are therefore not binding. As previously mentioned, the amounts of contaminants found in inks are highly dependent on the analytical method used. Furthermore, when the amount of ink in the skin is taken into consideration, the amount of contaminants in the skin becomes extremely small. The microwave digestion method has failed in the evaluation of barium and copper, and the results achieved for nickel are questionable.

The limit for nickel in the resolution ResAP(2008)1 is 'as low as technically achievable'. Of course, products containing no nickel can be found on the market, e.g. a simple black pigment, but this cannot be the reason for the use of a general limit of zero. Whether zero nickel is achievable also depends upon whether an ink contains organic or inorganic pigments. For inorganic iron oxides, a limit of zero is not 'technically achievable'.
The limits for some metals in ResAP(2008)1 are similar to those for drinking water. The level for nickel according to the drinking water regulation in Germany is $0.02 \mathrm{mg} / \mathrm{l}$, which is approximately $0.02 \mathrm{mg} / \mathrm{kg}$ [15]. As previously mentioned, the large tattoo performed at $\mathrm{CTL}^{\circledR}$ with the banned ink containing $12.2 \mathrm{mg} / \mathrm{kg}$ of nickel contained as little as $0.0057 \mathrm{mg}$ of nickel. This is well below the set limits for drinking water in Germany. It should be further considered that the intake of water is at least $1 \mathrm{~kg}$ every day for 365 days a year. A tattoo, on the other hand, should have a lifetime of 20 years, and ink is therefore only applied once every 20 years. Considering the legal limits for jewellery [11] and comparing them to those of tattoos reveals the following:

- the legal limit for nickel release in jewellery is $0.2 \mu \mathrm{g} / \mathrm{cm}^{2} /$ week; and

- the average content of nickel in large tattoos using the values from the above-mentioned banned ink is $0.006 \mu \mathrm{g} / \mathrm{cm}^{2}$.

This comparison shows that the amount of nickel in the skin is substantially (approximately 33 times) lower than the legal limit for nickel in jewellery.

Irrespective of whether ResAP(2008) 1 refers to soluble or insoluble metals, it is questionable whether these limits are realistic. Quite obviously, factors such as the amount of ink in the skin, daily uptake or daily consumption, total uptake and frequency of use have not been taken into consideration. Comparisons with several food products consumed on a daily basis by many people have shown that these foods contain as much nickel as the above-mentioned $910-\mathrm{cm}^{2}$ tattoo, which will only be performed once in a span of 20 years.

It must be mentioned that iron oxide-based inks are also used in hospitals for areola tattooing after breast reconstruction or breast cancer. In addition, these inks are used following the development of alopecia after chemotherapy or for cosmetic corrections after burns. This cosmetic 
tattooing improves the quality of life for many people. In particular, iron oxide pigments allow for the imitation of skin colour. If the limits for nickel in ResAP(2008)1 are enforced and the use of the microwave digestion method is required, then practically all iron oxide-based inks would become illegal.
The analysed amount of ink in the skin resulting from tattooing has been used here only for calculations of the resulting quantities of metal impurities in the skin. This fundamental data can also be used to calculate the actual amounts of other contaminants in the skin, which are listed in the resolutions of the $\mathrm{CoE}$.

\section{References}

1 Prior G: Tattoo Inks: Analysis, Pigments, Legislation. Berlin, epubli, 2014.

2 Council of Europe, Committee of Ministers: Resolution ResAP(2003)2 on Tattoos and Permanent Make-Up. Strasbourg, France, Council of Europe, 2003.

3 Council of Europe, Committee of Ministers: Resolution ResAP(2008)1 on Tattoos and Permanent Make-Up. Strasbourg, France, Council of Europe, 2008

4 Radiology dye kills six. The Age, Fairfax Digital, 2003. http://www.theage.com. au/articles/2003/07/23/1058853117047. html (accessed February 10, 2014).

5 Johnson CH, VanTassell VJ: Acute barium poisoning with respiratory failure and rhabdomyolysis. Ann Emerg Med 1991;20:1138-1142.

6 Ghose A, Sayeed AA, Hossain A, Rahman R, Faiz A, Haque G: Mass barium carbonate poisoning with fatal outcome, lessons learned: a case series. Cases J 2009;2:9327.
7 Commission of the European Communities: Fifth Commission Directive 93/73/EEC of 9 September 1993 on the methods of analysis necessary for checking composition of cosmetic products. Official Journal of the European Communities 1993;L 231:34-53.

8 Eurpopäisches Arzneibuch (European Pharmacopoeia). Stuttgart, Deutscher Apotheker Verlag, 1997.

9 Rehn L: Blasengeschwülste bei fuchsinarbeitern. Arch Klein Chir 1895;50:588600 .

10 Golka K, Kopps S, Myslak ZW: Carcinogenicity of azo colorants: influence of solubility and bioavailability. Toxicol Lett 2004;151:203-210.
11 DIN EN 1811:2012-10, Reference test method for release of nickel from all post assemblies which are inserted into pierced parts of the human body and articles intended to come into direct and prolonged contact with the skin. Berlin, Beuth Verlag, 2012.

12 CEN EN 71-3:2013 Safety of toys - Part 3: Migration of certain elements. European Committee for Standardisation, Brussels, 2013.

13 Basketer DA, Angelini G, Ingber A, Kern PS, Menné T: Nickel, chromium and cobalt in consumer products: revisiting safe levels in the new millenium. Contact Dermatitis 2003;49:1-7.

14 Fischer LA, Menné T, Johansen JD: Experimental nickel elicitation thresholds - a review focusing on occluded nickel exposure. Contact Dermatitis 2005;52:57-64.

15 Bundesgesetzblatt Teil 1, BGBI. I 2013, 2993 - 2995, Anlage 2 zu § 6 Absatz 2), Chemische Parameter.

Gerald Prior

CTL Bielefeld GmbH

Krackserstrasse 12

DE-33659 Bielefeld (Germany)

E-Mail info@ctl-bielefeld.de 